\title{
Effects of Heating Rate and Strain Rate on Phase Transformation in Micro-Grinding
}

\author{
Gaoxiang Sun ${ }^{1}$ and Zishan Ding, \\ ${ }^{1}$ School of Mechanical Engineering, University of Shanghai for Science and Technology, CN-200093, Shanghai, China
}

\begin{abstract}
The phase transformation in the grinding process could have a significant impact on the processing performance of the products. Although grinding process can lead to high heating and strain rates, the current studies on the phase transformation typically consider temperature only that limits their accuracy. In this study, based on the phase transformation model, by conducting the micro-grinding experiment of maraging steel C250, the mechanism controlling impacts of heating and strain rates on phase transformation has been analyzed, and a new process optimization scheme to control phase transformation has been proposed. In this research was determinate main characteristic parameters of the phase transformation prediction model and influence of the heating rate parameters on the structure of the material. The main conclusions of this work are aimed increasing productivity, as well as criteria for optimizing the micro grinding process are defined.
\end{abstract}

\section{Introduction}

The grinding process is distinct from that of general machining, due to plenty of heat generated between the grinding wheel and the workpiece that induces phase transformations [1] affecting the final microstructure and properties of the material. Without considering the evolution of metallographic structure induced by force and thermal load in the machining, it is impossible to ensure that the working performance of the final parts meets the requirements of material selection.

Phase transformation exerts a significant influence on both residual stress and surface quality of the workpiece. In general, the performance requirements can be met by imposing control over the transformation of martensite into different ratios of austenite [2]. The phase transformation occurring in the process of grinding can affect surface integrity [3]. During the process of phase transformation, the volume fraction of austenite changes [4], that can affect the microstructure, lead to strain hardening [5], and impact the residual stress of the workpiece [6]. Both phase transformation and residual stress can be effectively controlled by setting proper process parameters $[7,8]$.

The key advantage of phase transformation prediction models is that they are capable to make accurate prediction of the change to phase volume fraction at each stage of grinding temperature rising and cooling. A majority of the classical phase transformation prediction models consider only temperature only that limit their accuracy in calculating the grinding phase transformation. Moreover, the mechanism of the effect of heating rate and strain rate on the phase transition process in the grinding process is still unclear.
In this paper, by conducting tests on the surface phase composition of workpiece before and after grinding under different grinding parameters, the characteristic parameters of phase transformation prediction model have been determined. The impacts of heating rate and strain rate on phase transformation have been further analysed, and mechanism of phase transformation in the grinding process has been revealed.

\section{Theoretical basis of analytical model}

The geometric relationship between the grinding wheel and the workpiece during the grinding process as shown in Fig. 1.
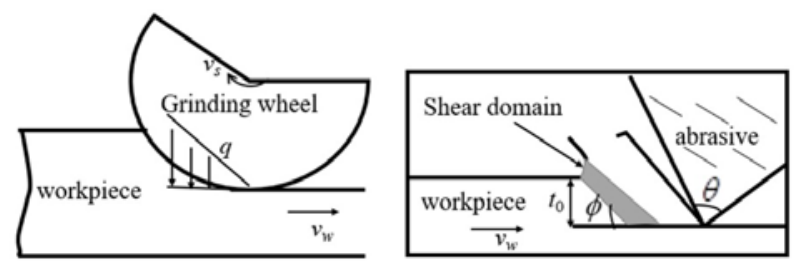

Fig. 1. Geometric relationship of grinding process.

Based on the assumptions of the moving heat source model, the heating rate can be expressed as:

$$
\dot{T}=\left(T-{ }_{r} / c / w_{\max }\right.
$$

where $T_{r}$ is the room temperature, $v_{w}$ is the workpiece feed rate, $l_{c}$ represents the length of the contact zone, which can be expressed as: 


$$
l_{c}=\sqrt{a_{p} \cdot d_{w}}
$$

where $d_{w}$ is the grinding wheel diameter, $a_{p}$ is the cutting depth. $T_{\max }$ is the highest temperature in the arc zone of the grinding surface, which can be obtained according to the triangular heat flux distribution model [9], it can be expressed as follows:

$$
T_{\max }=\frac{q}{\pi \lambda} \cdot \int_{-I_{c}}^{l_{c}} e^{\frac{-v_{w}(x-\xi)}{2 \mu}} K_{0}\left\{\frac{v_{w}}{2 \mu}\left[(x-\xi)^{2}+z^{2}\right]^{1 / 2}\right\} d \xi
$$

where $\lambda$ is the material thermal conductivity of workpiece, $\xi$ is the local coordinate, $\mu$ is the material thermal diffusivity of workpiece, $K_{0}$ is the second kind modified Bessel function, $z$ is the distance to the grinding surface, and $q$ is the heat flux over the contact length [10], which can be estimated as follows:

$$
q=\eta\left(\frac{u a_{p} v_{w}}{l_{c}}\right)
$$

where $\eta$ is the energy partition into the workpiece, $u$ is the specific energy, which can be expressed as follows:

$$
u=\frac{F_{t} v_{s}}{a_{p} v_{w}}
$$

The calculation of $T_{\max }$ needs to know the magnitude of tangential force $F_{t}$, which can be calculated as follows [11,12]:

$$
\begin{gathered}
F_{t}=F_{s g, t} \cdot C_{d} \cdot l_{c} \cdot b_{w} \\
F_{s g, t}=\int_{\alpha_{c r}}^{\alpha_{s}} \frac{\tau_{s} \cos \left(\beta_{i}-\alpha_{i}\right) \cdot 2 \mathrm{r}^{2} \cos ^{2} \alpha_{i}}{\left(\sin \phi_{i} \cos \left(\phi_{i}+\beta_{i}-\alpha_{i}\right)\right)} d \alpha
\end{gathered}
$$

where $b_{w}$ is the grinding wheel width, $F_{s g, t}$ is the tangential grinding force of a single abrasive particle, $\alpha_{c r}$ is the critical rake angle, $\alpha_{s}$ is the negative rake angle, $\tau_{s}$ is the shear strength of the material, $\beta_{i}$ is the instantaneous friction angle, $\alpha_{i}$ is the instantaneous rake angle, $\phi_{i}$ is the instantaneous shear angle. Based on the geometric relationship in grinding process, the dynamic abrasive grit density $C_{d}$ can be formulated with the following equation proposed by Hecker [13]:

$$
C_{d}=C_{s} /\left(1+\left(C_{s} / 4\right)\left(\tan (\theta) \xi^{3} / \tan (\varepsilon) z\right)\right)
$$

The parameter $\tan (\varepsilon)$ reflects the kinematic effects, can be expressed as follows:

$$
\tan (\varepsilon)=2 v_{w} a_{p} / v_{s} d_{\mathrm{w}}
$$

where $d_{w}$ is the grinding wheel diameter, $v_{w}$ is the feed rate, and $v_{s}$ is the grinding wheel speed.

The strain rate model of the shear region in the grinding process [14] can be expressed as:

$$
\dot{\varepsilon}=2 \lambda_{0} v_{s} \cos \alpha_{0} \sin \phi / t_{0} \cos \left(\phi+\alpha_{0}\right)
$$

where $\lambda_{0}$ is the length-to-width ratio in the shear zone, cutting rake angle $\alpha_{0}$ is equal to half of the cone angle $\theta, \phi$ is the shear angle, and $t_{0}$ is the thickness of undeformed chip. The classical Johnson-Mehl-Avrami (JMA) model and Koistinen-Marlburger (KM) model $[15,16]$ mainly consider the influence of temperature and time, a phase transformation prediction model considering both heating rate and strain rate has been proposed [17], which can be expressed as follows:

$$
\begin{aligned}
f & =f^{e q}\left\{1-\exp \left[-k(T, \mathbb{R}, \&](t)^{m\left(T, R^{\&} \&\right)}\right\}\right. \\
f_{\alpha^{\prime}} & =f_{\gamma}\left\{1-\exp \left[-\beta\left(M_{s}-T\right)\right]\right\} g(T, \mathcal{L}, \&)
\end{aligned}
$$

where $m, k$ and $g$ are functions of temperature, strain rate and heating rate, and their coefficients can be obtained by regression analysis, which can be expressed as:

$$
\begin{gathered}
m(T, \dot{T}, \dot{\varepsilon})=a_{m 1} \cdot T^{a_{m 2} \cdot \dot{T}^{a_{m 2}} \cdot \dot{\varepsilon}^{a_{m 4}}} \\
k(T, \dot{T}, \dot{\varepsilon})=a_{k 1} \cdot T^{a_{k 2}} \cdot \dot{T}^{a_{k 3}} \cdot \dot{\varepsilon}^{a_{k 4}} \\
g(T, \dot{T}, \dot{\varepsilon})=a_{g 1} \cdot T^{a_{g 2}} \cdot \dot{T}^{a_{g 3}} \cdot \dot{\varepsilon}^{a_{g 4}}
\end{gathered}
$$

\section{Materials and experiments}

Micro-grinding experiments were carried out on a Moore G18-CNC grinder. The maximum rotation speed of the motorized spindle ranges from 60,000 to $180,000 \mathrm{rpm}$, and the CBN grinding wheel with 230-grit is used in the experiment. The grinding temperature was measured with the assistance of DAQ (data acquisition equipment) thermometer and thermocouple, and the grinding force was determined by Kistler dynamometer. The phase compositions before and after grinding were obtained by the X-ray polycrystalline diffractometer. The relevant experimental and testing equipment is shown in Fig. 2.

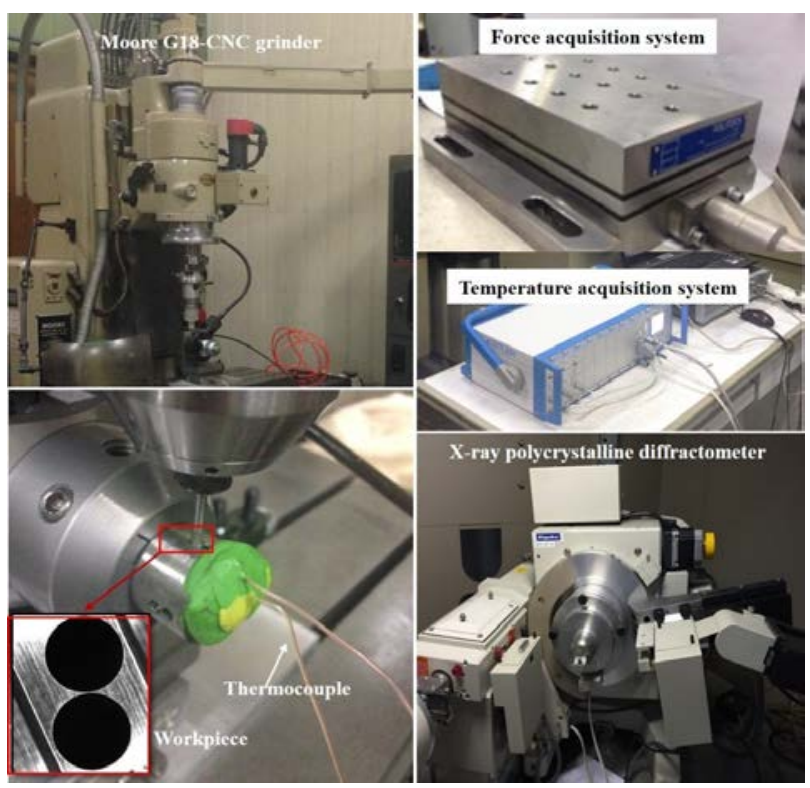

Fig. 2. Experimental and measuring equipment. 
The experimental material used in the research is maraging steel C250, its chemical composition as shown in Table 1. The micro-grinding experiment process parameters are shown in Table 2.

Table 1. Chemical composition of maraging steel (wt\%).

\begin{tabular}{llllllllll}
\hline Fe & $\mathrm{Al}$ & $\mathrm{Co}$ & $\mathrm{Mn}$ & $\mathrm{Ni}$ & $\mathrm{Si}$ & $\mathrm{Ti}$ & $\mathrm{B}$ & $\mathrm{C}$ & $\mathrm{S}$ \\
& & & & & & & & & \\
\hline 73. & 0.1 & 7.9 & 0.0 & 17. & 0.0 & 0.4 & 0.0 & 0.0 & 0.0 \\
56 & 2 & & 9 & 7 & 9 & 3 & 02 & 2 & 2 \\
\hline
\end{tabular}

Table 2. Different process parameters for the micro-grinding.

\begin{tabular}{lllll}
\hline & $\begin{array}{l}\text { Wheel } \\
\text { speed } \\
v_{s}[\mathrm{~m} / \mathrm{s}]\end{array}$ & $\begin{array}{l}\text { Workpiece } \\
\text { speed } \\
v_{w}[\mathrm{~m} / \mathrm{s}]\end{array}$ & $\begin{array}{l}\text { Depth of } \\
\text { cut } \\
a_{p}[\mu \mathrm{m}]\end{array}$ & $\begin{array}{l}\text { Material } \\
\text { removal rate } \\
Q^{\prime} w \\
{\left[\mathrm{~mm}^{3} / \mathrm{mms}\right]}\end{array}$ \\
\hline 1 & 6.28 & 0.0131 & 3 & 0.039 \\
2 & 6.28 & 0.0196 & 2 & 0.039 \\
3 & 6.28 & 0.0262 & 1.5 & 0.039 \\
4 & 9.42 & 0.0131 & 3 & 0.039 \\
5 & 9.42 & 0.0196 & 2 & 0.039 \\
6 & 9.42 & 0.0262 & 1.5 & 0.039 \\
7 & 12.56 & 0.0131 & 3 & 0.039 \\
8 & 12.56 & 0.0196 & 2 & 0.039 \\
9 & 12.56 & 0.0262 & 1.5 & 0.039 \\
\hline
\end{tabular}

After grinding, the surface of the workpiece was scanned by the $\mathrm{X}$-ray polycrystal diffractometer to determine the composition of the material. The phase PDF (Powder Diffraction File) cards were used to identify the peaks in the diffraction patterns, and the actual phase volume fraction change can be obtained by conducting the Jade software analysis.

\section{Results and discussions}

\subsection{Phase transformation test results}

The surface of the workpiece was scanned by using an X-ray polycrystal diffractometer to determine the composition of the material, and the phase transformation results as shown in Fig. 3.

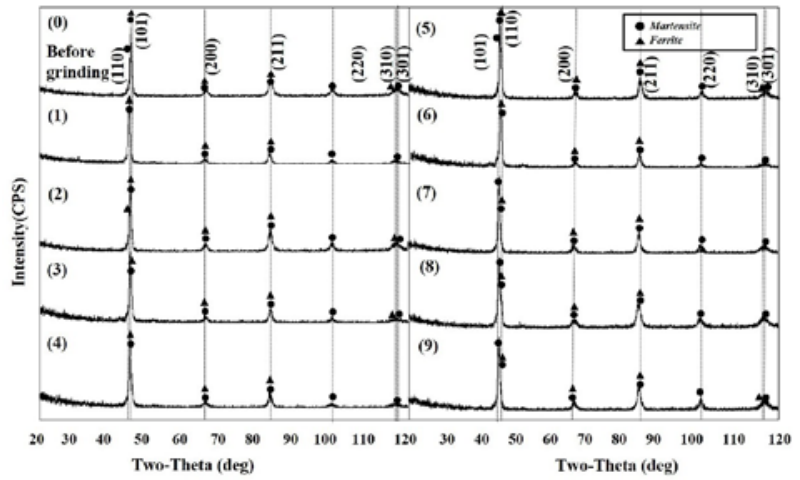

Fig. 3. Phase transformation curve results.

The evolution of phase volume fraction (PVF) is vitally important, the phase transformation ratio obtained from the grinding experiment is used to fit the characteristic coefficient of the prediction model. By comparing the prediction results of the model with the experimental results that did not participate in the regression analysis, it is found that the average prediction error of martensite and ferrite is less than $3.5 \%$ and $5.5 \%$, respectively. It can be considered that the prediction model is effectively, and the values of characteristic coefficient $\mathrm{m}, \mathrm{k}$ and $\mathrm{g}$ are as follows:

$$
\begin{aligned}
& m(T, \dot{T}, \dot{\varepsilon})=0.0006 \cdot T^{-1.5501} \cdot \dot{T}^{0.2289} \cdot \dot{\varepsilon}^{0.9354}(16) \\
& k(T, \dot{T}, \dot{\varepsilon})=0.0252 \cdot T^{-0.7465} \cdot \dot{T}^{0.0643} \cdot \dot{\varepsilon}^{0.4992}(17) \\
& g(T, \dot{T}, \dot{\varepsilon})=2.2270 \cdot T^{0.1381} \cdot \dot{T}^{0.0852} \cdot \dot{\varepsilon}^{-0.1330}(18)
\end{aligned}
$$

\subsection{Phase transformation mechanism}

The changes of grinding wheel speed, workpiece feed rate and cutting depth will affect the heating rate and strain rate. It can affect the metallographic structure through the force and thermal load, so the heating rate and strain rate can be controlled by controlling different grinding parameters, and then the process optimization parameters for controlling phase transformation can be obtained. The selected grinding parameters are as follows: grinding wheel speed is $6.28,9.42,12.56,15.70$ $\mathrm{m} / \mathrm{s}$, the workpiece feed rate is $0.0131,0.0196,0.0262$ $\mathrm{m} / \mathrm{s}$, and the cutting depth is $1.5,2,3 \mu \mathrm{m}$. The input process parameters are combined to calculate the phase transformation under different heating rate and strain rate through the phase transformation prediction model.

The relationship between heating rate and phase transformation showed in Fig. 4. 


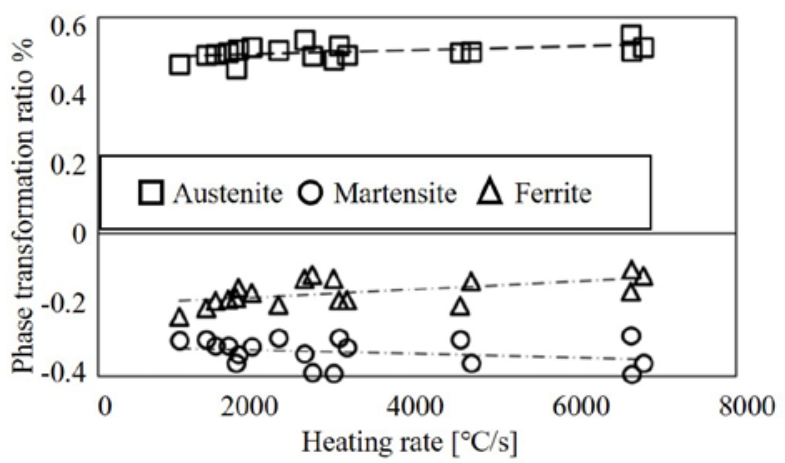

Fig. 4. Effects of heating rate on phase transformation.

As the heating rate is on the rise, austenite increases, while martensite and ferrite decrease, and the increase of heating rate is more likely to induce the transformation of martensite into austenite. The transformation of excessive martensite into austenite leads to the change in metallographic volume fraction and causes change to the microstructure and properties of the material. Martensite and ferrite show body-centered cubic structure, while austenite is of face-centered cubic structure. The transformation of too much martensite into austenite will cause uneven volume change and lead to residual stress. During the cooling process, austenite is inversely transformed into martensite and ferrite, and volume expansion occurs, which can reduce the residual stress difference caused by force and temperature in the grinding process and the processing deformation of materials. Therefore, the heating rate ought to be reduced and the cooling rate needs be increased to reduce the transformation from martensite into austenite.

The relationship between strain rate and phase transformation showed in Fig. 5.

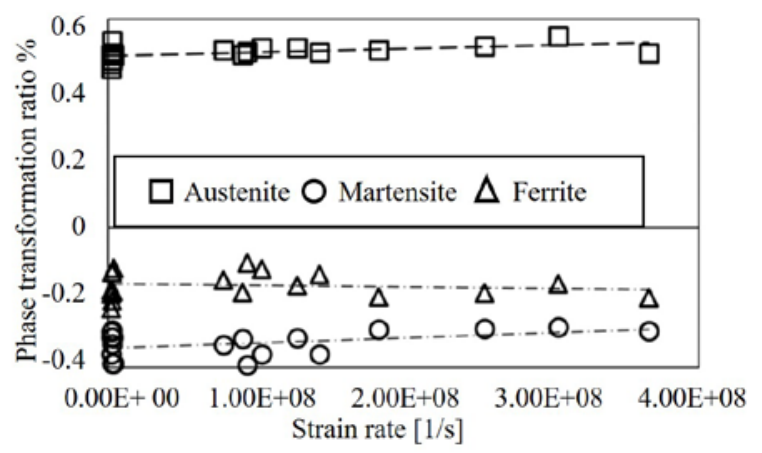

Fig. 5. Effects of strain rate on phase transformation.

With the increase of strain rate, more ferrite is transformed into austenite, while the transformation from martensite to austenite is reduced. The rise of strain rate can promote the diffusion of atoms near the grain boundary, and it is more likely to occur during the transformation from ferrite into Austenite resulting from atomic diffusion. Therefore, the strain rate can be appropriately increased to promote the transformation of ferrite into austenite, reduce the change in phase microstructure and composition during the grinding process, and facilitate the microstructure and properties of the machined materials to be stabilized.

\section{Conclusions}

By conducting the micro-hole grinding experiment, the phase transformation ratio was measured under different process parameters, the characteristic parameters of the phase transformation prediction model were determined, and mechanism controlling impacts of heating rate and strain rate on the phase transformation have been analysed. The present study leads us to the following conclusions:

1) In the process of grinding, the lower heating rate can reduce the transformation from martensite into austenite, thus reducing the residual stress difference and the deformation of materials.

2) By increasing the strain rate, the transformation from martensite into austenite can be reduced, while the transformation from ferrite into austenite can be promoted. It can be efficient in avoiding the performance change caused by excessive microstructural changes after grinding, and in improving surface quality.

3) The lower heating rate and higher strain rate can be used as the criteria of process optimization for the improvement in the performance of the workpiece.

This work was supported by the National Natural Science Foundation of China (grant number 51705323).

\section{References}

1. S.M. Shah, D. Nelias, M. Zain-ul-abdein, M. Coret, Finite. Elem. Anal. Des. 61, 1-11 (2012)

2. P.W. Hochanadel, C.V. Robino, G.R. Edwards, M.J. Cieslak, Metall. Mater. Trans. A. 25, 789-798 (1994)

3. C.J. Wu, J.Z. Pang, B.Z. Li, S.Y. Liang, Int. J. Adv. Manuf. Tech. 102, 1913-1921 (2019)

4. B. Avishan, Mater. Sci. Eng. A. 729, 362-369 (2018)

5. J. Sun, J. Hensel, J. Klassen, T. Nitschke-Pagel, K. Dilger, J. Mater. Process. Tech. 265, 173-184 (2019)

6. T. Otsuka, R. Brenner, B. Bacroix, Int. J. Eng. Sci. 127, 92-113 (2018)

7. J.M. Ni, B.Z. Li, Mater. Lett. 89, 150-152 (2012)

8. X.H. Jiang, X.J. Kong, Z.Y. Zhang, Z.P. Wu, Z.S. Ding, M.X. Guo, Int. J. Mech. Sci. 167 (2020)

9. C. Guo, S. Malkin, J. Eng. Indus. 117, 55-61 (1995)

10. H.J. Kim, N.K. Kim, J.S. Kwak, Int. J. Mach. Tool. Manu. 46, 2086-2093 (2006)

11. J.Y. Tang, J. Du, Y.P. Chen, J. Mat. Proc. Tech. 209, 2847-2854 (2009)

12. H.W. Park, S.Y. Liang, Int. J. Adv. Manuf. Tech. 44, 476-486 (2009)

13. R.L. Hecker, Ph.D. dissertation of Georgia Institute of Technology, Atlanta. (2002)

14. T. Jin, G. Cai, Chin. Mech. Eng. 12, 1401-1403 (1999) 
15. M. Avrami, J. Chem. Phys. 8, 212-224 (1940)

16. D.P. Kosistinen, R.E. Marburger, Acta. Metall. 7, 50-60 (1959)

17. Z.S. Ding, B.Z. Li, Y.M. Shao, S.Y. Liang, Mater. Manuf. Process. 31, 1763-1769 (2016)

18. A. Isaev; V. Grechishnikov; P. Pivkin, EpitoanyagJournal Of Silicate Based And Composite Materials, 68(2), 46-51 (2016)

19. V.A. Grechishnikov; Y.E. Petukhov; P.M. Pivkin, Measurement Techniques, 58(8), 848-853, (2015)

20. S.N. Grigoriev, M.P. Kozochkin, F.S. Sabirov, and A.A. Kutin, Proc. CIRP, 1, 599-604 (2012)

21. S.N. Grigoriev, V.A. Sinopalnikov, M.V. Tereshin, and V.D. Gurin, Measur. Techn., 55(5), 555-558 (2012) 